\title{
Seni Dalam Bingkai Budaya Mitis: Nilai Life Force dan Transformasinya ke Budaya Ontologis
}

\author{
Suharno \\ Jurusan Seni Rupa Institut Seni Budaya Indonesia (ISBI) Bandung \\ Jl. Buahbatu No 212 Bandung, 40265 \\ Emal: visnumurty@gmail.com
}

\begin{abstract}
This writing is aimed to formulate transformation theory of life force values in art of mystical culture area to ontology culture. The occurrence of this theory is very significant as it can be a tool to study the art in the past in the relation to the present, also stepping stone of scientific creation of present art that bases on cultural values of the past. The material object being studied is the character of Petruk in Purwa skin puppet (wayang). The method uses for that purpose is a conceptual approach. The result of the study shows that the transformation of life force values in the art of mystical culture area to ontology culture can be conducted if the creator is able to find, interpret, and apply those values into a contemporary work of art by regarding three basis of art creation; content, shape, and contextual art performance.
\end{abstract}

Keywords: transformation, life force value, mystical culture esthetics and ontologism

\begin{abstract}
ABSTRAK
Tulisan ini bertujuan merumuskan teori transformasi nilai-nilai life force dalam seni dari ranah budaya mitis ke budaya ontologis. Kehadiran teori ini cukup penting karena dapat menjadi salah satu sarana mengkaji seni masa lampau kaitannya dengan seni masa kini, serta pijakan ilmiah penciptaan karya seni masa kini yang berbasis nilai-nilai budaya masa lampau. Objek material yang dikaji adalah tokoh Petruk dalam wayang kulit purwa. Metode telaah yang digunakan untuk kepentingan tersebut adalah conceptual approach. Hasil kajian menunjukkan, bahwa transformasi nilai-nilai life force dalam seni dari ranah budaya mitis ke budaya ontologis dapat dilakukan jika kreator mampu menemukan, menginterpretasi, dan mengejawantahkan nilai- nilai tersebut ke dalam karya seni masa kini dengan memperhatikan tiga dasar penciptaan seni, yakni: isi, bentuk, dan penyajian karya yang kontekstual.
\end{abstract}

Kata kunci: tranformasi, nilai life force, estetika budaya mitis dan ontologis 


\section{PENDAHULUAN}

Seni adalah kebutuhan hidup manusia sepanjang jaman. Ia dihadirkan untuk memenuhi kebutuhan rohani manusia dengan kadar yang berbeda, mulai dari yang sekedar pemuas hasrat hingga sebagai media transendensi. Bagi masyarakat pramodern, seni adalah bagian tidak terpisahkan dari laku puja. Oleh sebab itu, wujud benda seninya merupakan pengejawantahan mitologi dan ritual masyarakat yang melahirkannya. Mitologi adalah aspek kepercayaannya, dan ritual adalah wujud pemujaannya.

Salah satu warisan seni pramodern adalah wayang kulit purwa. Akar seni ini adalah ritus purba, yakni pemujaan terhadap arwah nenek moyang. Seiring datangnya pengaruh kebudayaan Hindu bersama Mahabharata ke Asia yang menurut Sharma sebelum kurun waktu Masehi (Widyaseputra, 2007: 120) orientasi pemujaan dalam wayangpun berubah, yakni kepada dewa-dewi dalam Veda. Untuk keperluan pemujaan terhadap nenek moyang, maka tema-tema viracarita Mahabharata dan Ramayana dipakai sebagai landasan pementasannya (Widyaseputra, 2001: 195).

Salah satu jejak pertunjukan wayang kulit purwa sebagai sarana puja kepada arwah leluhur dapat ditemukan dalam lakon wayang, seperti Pandu Swarga dan Semar Mbangun Kahyangan. Lakon Pandu Swarga digunakan untuk upacara nyewu (Widyaseputra, 2001: 198) dan lakon Semar Mbangun Kahyangan digunakan untuk upacara nyadran. Nyewu adalah upacara peringatan seribu hari meninggalnya seseorang. Adapun nyadran merupakan perwujudan pengagungan terhadap arwah leluhur (Partokusumo, 1995: 246-247; Alifiana, 2013: 108), dan merupakan bentuk transformasi dari ritus penyempurnaan arwah yang dalam kitab Negarakertagama disebut sraddha (Earl Drake, 2012 : 157).

Jejak pemujaan terhadap dewa-dewi Hindu dapat dilihat pada lakon Sri Mulih dan Tumurunipun Taman Maerakaca dalam tradisi wayang Yogyakarta. Lakon Sri Mulih dan variannya (Sri Bali, Sri Mantuk) digunakan untuk upacara kesuburan/ruwat bumi. Lakon ini merupakan bentuk penaratifan ritus puja kepada Dewi Sri yang ada dalam tradisi vîracarita dan Tantris, yakni pemujaan kepada Devî Bhûmi yang dikenal dengan nama Durgâ, Devî, Úakti, Pârvatî, Umâ, dan Ambikâ. Adapun lakon Tumurunipun Taman Maerakaca pada dasarnya merupakan penaratifan upacara ritual dalam tradisi Veda, yaitu upacara Agnihotra (Widyaseputra, 2012: 40-42, 46-47).

Adanya kesinambungan tradisi Veda dan ritus purba dalam lakon wayang Jawa menandakan bahwa telah terjadi penjawaan terhadap Mahabarata dan Ramayana. Kedua kitab tersebut awalnya disebarkan secara lisan dan baru digubah dalam bentuk tulis pada abad ke-9 dengan huruf Jawa Kuna berbahasa Jawa Kuna (Lombard, 1996: 6; Poerbatjaraka, 1957: 23). Adapun penjawaan Mahabharata Sansekerta menjadi parwa-parwa dalam Jawa Kuno yang dalam istilah Supomo disebut adaptasi, terjadi pada abad $\mathrm{X}$ pada masa Úrî Dharmavamúa Têguh Anantavikramôtunggadeva (Widyaseputra, 2009: 2).

Hal penting dari adaptasi di atas adalah ditempatkannya dewa-dewa Hindu di bawah tokoh mitologi lokal (arwah nenek moyang) yang kemudian diwujudkan dalam bentuk wayang panakawan. Kitab Tantu Pangglaran yang digubah pada awal abad ke $16 \mathrm{M}$, kian menegaskan bahwa kedudukan para dewa semakin direndahkan di bawah para pendeta dan nenek moyang orang Jawa sendiri (Munandar, 2009: 9). Oleh sebab itu tidak ada satupun 
tokoh dalam cerita Mahabharata dan Ramayana versi Jawa yang dapat mengalahkan Semar dan anak-anaknya. Mereka ini adalah tokoh yang merepresentasikan eksistensi leluhur Jawa, dan karenanya menempati kedudukan penting dalam setiap struktur bangunan lakon wayang hingga saat ini. Tidak hanya itu, peran panakawan telah menjadi inspirasi penciptaan karya seni di luar wayang kulit purwa, seperti poster, komik, wayang hiphop, dan sebagainya. Hadirnya panakawan dalam bentuk dan fungsi baru ini tentu menunjukkan bahwa ada nilai daya hidup (life force) dari wayang panakawan yang dapat ditransformasikan ke dalam karya seni kekinian sesuai konteksnya. Sudah barang tentu dalam transformasi tersebut memerlukan landasan teoritis, dan tulisan ini akan mewujudkannya.

\section{METODE}

Metode yang digunakan untuk mengkaji persoalan adalah conceptual approach, yakni metode studi ilmiah yang memberikan tekanan utama pada penjelasan konsep-konsep dasar yang kemudian dipergunakan sebagai sarana analisa dan konstruksi (Soekamto, 1985: 32). Konsep pokok yang ditelaah adalah nilai life-force, estetika budaya mitis dan ontologis, serta transformasi. Adapun objek materialnya adalah wayang panakawan tokoh Petruk dalam tradisi wayang kulit purwa gaya Yogyakarta.

Panakawan adalah tokoh batur atau pangembating catur (Poerwadarminta, 1939: 462), yakni hamba sahaya yang bertugas sebagai pengiring dan teman diskusi kesatria/raja Jawa dalam menentukan langkah lahir dan batin. Menurut Wieringa (Munandar 2009: 12), istilah punakawan pertama kali disebut dalam Gatotkacacraya gubahan Mpu Panuluh abad ke 12, dengan nama Punta dan Prasanta. Keduanya adalah pengasuh para remaja keluarga raja yang disebut dengan jabatan Juru Dyah. Petruk sendiri termasuk tokoh panakawan pendamping kesatria berwatak baik, dan karenanya termasuk panakawan tengen atau kanan (Gampang, 1956: 15-16; Machfoeld, 1976: 63).

Petruk menjadi penting karena merupakan panakawan yang dalam pagelaran wayang kulit purwa gaya Yogyakarta cukup unik. Pertama, suara Petruk adalah suara asli dalang. Dalang tidak perlu memproduksi suara khusus untuk memperoleh karakter tertentu, seperti suara untuk Arjuna, raksasa, dan sebagainya. Hal ini tentu memerlukan penelitian tersendiri dan sedang didalami penulis. Kedua, wujud Petruk berbeda dengan bentuk awal penggambaran panakawan di abad XIII yang gempal, pendek/cebol, dan gemuk yang secara arkeologis dapat ditemukan di Candi Jago (Munandar, 2009: 7-8), candi Tegawangi (Sedyawati, 2009: 4), dan di muka gapura Candi Gedong I di Situs Muarajambi (Atmodjo, 2009: 6).

\section{HASIL DAN PEMBAHASAN \\ Nilai Life Force}

Life force dalam konteks kesenian adalah cetusan M. Dwi Marianto dalam artikelnya "Relasi Bolak-balik Antara Seni dan Daya Hidup" (2010: 143-158). Menurutnya, seni yang memiliki daya hidup adalah seni yang memiliki levitational force, yakni daya yang merangsang terbangunnya keinginan seseorang untuk melakukan sesuatu yang sesuai rangsangan yang ditimbulkan oleh suatu subjek. Oleh karena itu, menurutnya seni atau berkesenian yang baik dan mencerahkan adalah yang mampu membangkitkan daya hidup bagi mereka yang terlibat, minimal bagi praktisinya, dan selalu bergerak dan muncul melalui 
berbagai aktivitas kehidupan sehari-hari yang dilakukan sedemikian rupa guna membuat hidup lebih indah, menggairahkan, dan merangsang masyarakat untuk melanjutkan dan memaknai kehidupan.

Berdasarkan pemahaman di atas, maka yang dimaksud dengan nilai life force dalam seni adalah nilai-nilai tertentu di dalam karya seni dan atau aktivitas seni yang berdaya levitasional, sehingga karya seni/ aktivitas seni tersebut mampu membangkitkan daya hidup masyarakat sesuai konteksnya secara khas. Nilai-nilai tersebut bisa nilai sakral maupun profan.

\section{Estetika dalam Budaya Mitis dan Ontologis}

Budaya mitis adalah budaya yang menempatkan subjek dengan objek belum ada pemisah jelas. Aku masih terkepung kekuatan gaib di sekitarnya, sehingga selalu turut mengambil bagian dalam kejadian sekitarnya, melebur dengan kekuatan-kekuatan alam ke dalam suatu partisipasi. Adapun budaya ontologis adalah budaya yang telah menempatkan aku mampu mengambil jarak dari kekuatan dalam lingkungan (Noerhadi, 1984: 36-38, 203-211). Budaya mitis dengan demikian adalah budaya yang dilandasi pemikiran bahwa manusia adalah bagian dari alam. Pemikiran ini adalah ciri budaya pramodern, dan pengetahuan tertinggi manusia pramodern Indonesia adalah pengetahuan penyatuan dengan totalitas. Adapun berpikir secara ontologis adalah selalu membuat ja-rak dengan objek pengetahuan. Pengetahuan harus dapat dibuktikan secara em-piris dan secara rasionallogis (Sumardjo, 2006: 5-7).

Perbedaan cara pikir di atas menjadikan estetika seni dalam budaya mitis dan estetika seni modern yang ontologis berbeda (Sumardjo, 2000: 319322). Seni dalam bingkai budaya mitis diciptakan untuk fungsi mitologi-ritual, sehingga estetikanya mengikuti pola pikir mitologi-ritual yang mendasarinya. Estetika ranah ini mengutamakan kelangsungan hidup secara kosmis, berorientasi pada alam ruh atau goib, sehingga tanda rupa dibentuk bukan untuk tujuan estetika, tetapi untuk bersatu dengan "Ruang Asal", sementara estetika dunia modern berlandaskan pada mentalitas budaya yang berdasarkan sistem inderawi, terukur, teraba, dan kongkrit (Riyanto, 2002: 62-63). Oleh karena berdasarkan sistem inderawi, maka konsep estetika seni modern terus berubah. Perubahan konsep estetik kemodernan dalam seni ini menurut Sugiharto dalam artikelnya "Gelagat Post-estetik dalam Seni Kontemporer" (2008) ditandai dengan disangkalnya terus-menerus konsep-konsep sebelumnya, hingga akhirnya disangkalnya kata "kesenian" itu sendiri. Hal ini disebabkan oleh kecenderungan "diskontinuitas" dalam rangka mencari "originalitas", atau kecenderungan "Avantgarde" untuk senantiasa bereksperimentasi mencari kebaruan tak habis-habisnya.

Berangkat dari paparan di atas, nampaklah bahwa estetika dalam budaya mitis dan ontologis bertolak belakang karena latar belakang produksi estetiknya berbeda. Walaupun demikian keduanya dapat dipadukan, dan paduan yang baik tentu bukan sekedar memungut masa lalu dan menempelkan ke masa kini, namun harus dibarengi pemahaman komprehensif tentang konteks kultural dari seni budaya mitis dan ontologis, sehingga "ruh" budaya mitis dapat dibawa ke medan seni kekinian sesuai konteksnya yang khas.

\section{Tranformasi Nilai Life Force dari Budaya Mitis ke Ontologis}

Transformasi adalah alih rupa, yakni perubahan pada tataran permukaan, 
sedang pada tataran yang lebih dalam tidak terjadi perubahan (Putra, 2001: 62-63). Contoh alih rupa dalam pertunjukan Wayang Kulit Purwa adalah Bathara Guru berubah wujud menjadi Resi Wisuna dalam lakon Semar Gugat dan Arjuna berubah menjadi seekor harimau dalam lakon Semar Mbangun Kayangan versi Ki Hadisugito. Resi Wisuna dan harimau adalah wujud transformasi dari wujud Batara Guru dan Arjuna. Wujudnya memang berubah, namun lapis dalamnya (esensi) keduanya tidak berubah. Hal ini menunjukkan, bahwa wujud wayang kulit purwa memiliki dua lapis, yakni lapis luar dan lapis dalam. Lapis luar adalah substansi (wadah), yakni wujud/bentuk wayang itu sendiri. Lapis dalam adalah esensi/isi, yakni nilai simbolik eksistensial manusia yang diwujudkan dalam bentuk wayang itu sendiri. Berdasarkan pemahaman ini jelaslah bahwa lapis luar dari tokoh Petruk adalah wujud tokoh tersebut dengan segala atributnya, sedangkan lapis dalamnya adalah esensi Petruk, yakni nilai simbolik kesejatian Petruk yang memiliki daya levitasional. Nilai ini dapat ditelusuri dari wujud dan perannya dalam lakon wayang serta dalam kehidupan yang sesungguhnya, karena keberadaan Petruk dikaitkan dengan salah satu titik kekuatan sakral di tanah Jawa, yakni gunung Merapi (Stange, 1998: 135136).

\section{Wujud, Peran, dan Esensi Panakawan}

Wujud tokoh wayang dan perannya dalam lakon adalah satu kesatuan, karena peran berkait dengan karakter, dan karakter berkait dengan tanda rupa yang mewujud dalam figur tokoh tersebut. Wujud Petruk sendiri memiliki beragam bentuk karena setiap daerah pewaris wayang kulit purwa memiliki gayanya sendiri, namun sebagaimana panakawan lainnya Petruk diwujud- kan bertolak belakang dengan wujud tuannya. Arjuna contohnya, digambarkan sempurna, sementara Petruk memiliki cacat fisik, seperti tubuhnya serba panjang dan pusarnya bodong (menonjol keluar).

Secara arkeologis, penggambaran pertama kali figur panakawan yang "buruk rupa" ditemukan di masa Majapahit, yakni dalam bentuk relief di Candi Jago, yang sangat mungkin didasarkan kepada hubungan Raden Wijaya dengan para pengiringnya di akhir abad XIII (Munandar 2009: 12). Penggambaran panakawan yang "buruk rupa" pada zaman Majapahit itu tersirat pula di relief candi Tegawangi. Adapun data sastra (kakawin maupun kidung) yang ditulis di zaman Majapahit tidak menggambarkan sosok panakawan sebagai tokoh yang jelas perangai dan peranannya (Sedyawati, 2009: 4).

Penggambaran panakawan yang "buruk rupa" ini menurut Munandar (2009: 13) adalah untuk menunjukkan bahwa mereka adalah orang desa, pribumi asli, pendeta Jawa yang bukan dari kalangan brahmana sebagaimana para pendeta istana, namun kesaktiannya jauh lebih tinggi dari pada dewa dewa Hindu dari India. Pandangan inilah yang menjadikan panakawan dilibatkan dalam upacara-upacara suci kerajaan karena dianggap memiliki kekuatan magis (periksa Soelarto, 1993: 86-87; Lombard, 1996: 130-131).

Penggambaran wujud panakawan yang bertolak belakang dengan tuannya, kiranya juga untuk meneguhkan konsep dualime yang saling melengkapi, yakni manunggaling kawula-gusti dalam tataran horisontal. Panakawan adalah kawula (rakyat), dan para raja adalah gusti. Keduanya memiliki tanggung jawab sesuai kapasitasnya masing-masing yang saling melengkapi, sehingga melahirkan harmonitas sosial (Suharno, 2009: 45-47). 
Sebagaimana panakawan lainnya, peran Petruk dalam lakon wayang adalah sebagai abdi yang mendampingi tuannya dalam menentukan arah tindakan berdimensi lahir batin berdasarkan nilai dan norma yang terkandung dalam Mahabarata dan Ramayana. Peran ini memiliki akar kultural yang secara historis dapat dilihat dari prasasti Pucangan (963 Saka/1401 M). Prasasti ini menyatakan bahwa selama Airlangga mengungsi dan tinggal di dalam hutan selalu ditemani oleh abdi setianya yang bernama Narottama. Menurut Munandar (2009: 3-4), tradisi ini sangat mungkin telah terjadi pada zaman sebelum Airlangga, hanya saja tidak ada berita tertulis apapun sehingga sukar mencari bukti buktinya. Munandar juga menegaskan, bahwa satria yang berkelana selain ditemani oleh dewa pribadinya yang bersemayam dalam hatinya (ista dewata), secara konkret dalam pengisahan Jawa Kuno didampingi pula oleh tokoh tokoh sakti namun berpenampilan lucu, sederhana, atau agak tidak sempurna tubuhnya, yang dalam kakawin Gatotkacaœraya, dinamakan Juru Dyah. Karya Mpu Panuluh inilah yang pertama kali menyebutkan adanya tokoh panakawan pengiring satria (Abimanyu) yang sebelumnya tidak pernah dikenal dalam epik Mahabarata atau Ramayana India (Munandar, 2009; 5; Zoetmulder, 1983: 332-338; Poerbatjaraka, 1957: 32; Timoer, 1988: 54).

Hadirnya panakawan sebagai pendamping tuannya dalam menentukan kebijakan berdasarkan nilai dan norma Mahabarata dan Ramayana, kiranya bukan semata meneruskan tradisi pola hubungan kawula-gusti, namun sebagai wahana komunikasi simbolik. Damono (2009: 2) mensinyalir hadirnya panakawan adalah untuk memudahkan dalam menjelaskan nilai dan norma Mahabarata dan Ramayana yang rumit, pelik, dan subtil kepada penonton wayang yang uncultured dan unlittered. Proposisi Damono ini menunjukkan bahwa panakawan dalam konteks seni pertunjukan Wayang Kulit Purwa mewadahi sistem komunikasi simbolik. Secara lahiriah, panakawan bertugas memberikan penjelasan persoalan pelik yang tidak bisa dipecahkan oleh tuannya, namun sebenarnya ia menjelaskan kepada penonton yang uncultured dan unlitered. Hal inilah yang menjadikan panakawan memiliki daya hidup, memilki daya levitasional, karena menjadi pintu kesadaran kolektif masyarakat Jawa, bahwa leluhur yang diejawantahkan dalam wujud rakyat jelata memiliki peran signifikan terhadap kelangsungan bangsa dan negara, sehingga aktivitas ritus puja terhadap leluhur untuk keselamatan bersama masih bisa ditemukan hingga saat ini.

Berpijak dari pemahaman di atas, nampak bahwa dari sisi mitologi, esensi panakawan adalah leluhur Jawa yang memiliki kesaktian melebihi dewa-dewa Hindu. Leluhur inilah yang diyakini momong (mengasuh) manusia Jawa dalam setiap jaman. Oleh sebab itu panakawan selalu hadir dari waktu ke waktu. Di jaman purwa hadir Semar, Gareng, Petruk, dan Bagong; di jaman madya tampil Bancak dan Doyok; di jaman panji tampil Jurudyah dan Punta (Pradipta, 2009: 5; Yusuf, 2009: 3-4); dan di jaman Majapahit muncul Sabdopalon Nayagenggong, yang tidak lain adalah panakawan Damarwulan (Tedjowirawan, 2009: 1).

Pengagungan terhadap leluhur Jawa mencapai puncaknya di jaman Majapahit akhir, yakni pada peristiwa sumpah Sabdopalon Nayagenggong yang tidak bersedia mengikuti raja Brawijaya $\mathrm{V}$ yang diasuhnya memeluk agama Islam (Dipokusumo, 2009: 1-2). Sumpah itu menjadikan 
keduanya sebagai sosok cultural hero karena membela mati-matian ideologi agama Siwa-Budha dari Islam (Pradipta, 2009: 7). Bahkan hingga kini, ritus pemujaan makam Sabdapalon di bukit tidar Magelang serta ritus pemanggilan Semar oleh sekelompok pemujaan di Surakarta yang memusatkan pada Semar masih bisa dijumpai (Stange, 1998: 134-135, 139-140, 151-153).

\section{Esensi Petruk dan Transformasinya}

Esensi Petruk ada di balik wujud dan konteks perannya dalam lakon wayang. Petruk dalam tradisi pewayangan gaya Yogyakarta (gambar 1) digambarkan berkucir, berhidung panjang, telinga besar, tangan depan menunjuk dengan dua jari, tangan belakang mengepal, pusar bodong (menonjol keluar), berkalung klinthing, bersenjata kapak (pethel), berkain slobog, dan bersepatu dengan kaki depan jinjit.

Menurut Widyaseputra (Kuntara, 2009: 2), penggambaran yang serba panjang untuk menandakan bahwa Petruk adalah panjang sabar, panjang ilmu, panjang budi. Kucirnya yang panjang adalah kucir keramat, sehingga Arjuna pernah bertapa di kucir tersebut. Ketika Petruk lahir kucirnya berlumuran darah, kemudian dibersihkan dengan air liur burung Sendari Putih. Darah yang mengalir dari kucir menjadi senjata kapak yang dapat mewakili dirinya (lakon Resi Bandulan Jagad). Hidung panjang melambangkan memliki daya penciuman yang tinggi. Petruk mampu mendeteksi Bisma (bau bunga srigading), Janaka (bau bunga melati), dan Puntadewa berbau bunga gambir (lakon Seta Ngraman). Telinga besar melambangkan kemampuan Petruk dalam membedakan yang asli dengan yang palsu melalui telinganya (lakon Gathutkaca Kembar). Tangan depan menunjuk dengan dua jari artinya menunjuk hal ihwal ilahi dan duniawi, batin dan

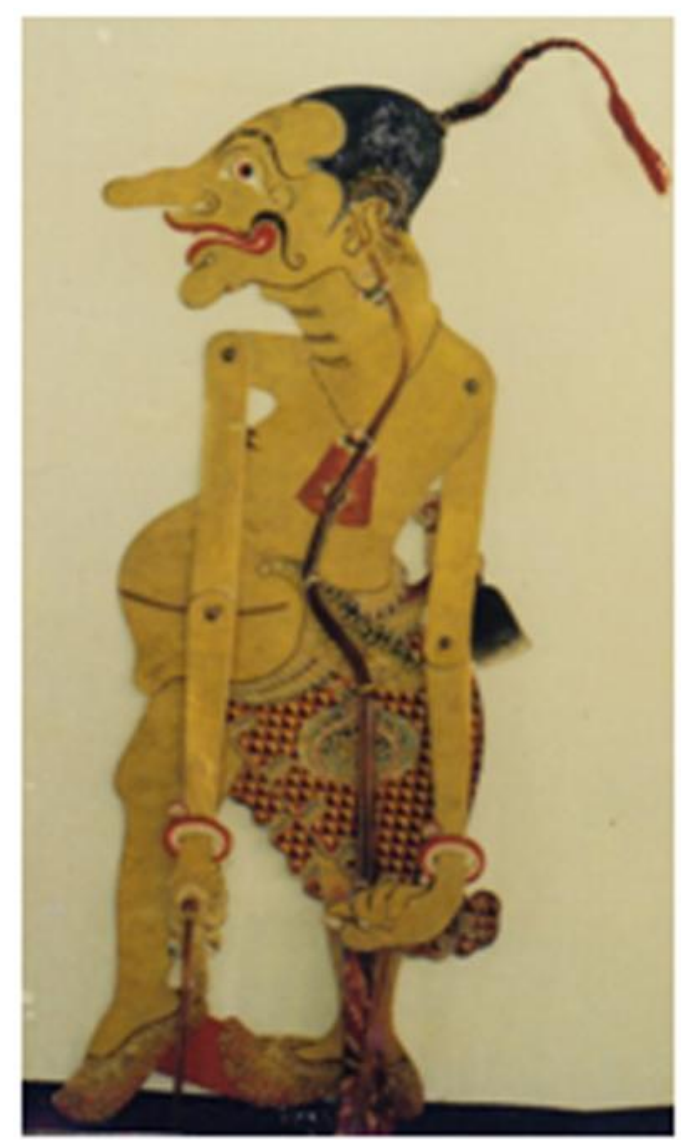

Gambar 1: Petruk Gaya Yogyakarta koleksi keraton Yogyakarta Sumber : Wiwoho (2001: 64)

lahir, baik dan buruk. Tangan belakang mengepal artinya menyimpan rahasia Ilahi. Pusar bodong menunjukkan bahwa tuan yang dilayani hidup makmur, tahu sangkan paraning dumadi (asal dan tujuan makhluk). Kalung klinthing gunanya untuk memanggil dewa. Jika ingin memanggil dewa cukup hanya dengan membunyikannya. Klinthing tersebut berasal dari potongan tali pusarnya. Kain slobog melambangkan Petruk bisa manjing ajur ajer (pandai bergaul). Kaki depan jinjit, menunjukkan sikap brahmana, yang waspada dan berhati hati dalam bertindak

Paparan di atas menunjukkan dua hal. Pertama, sebagai anak angkat Semar-Petruk adalah anak begawan Druwa dengan Bathari Purnaningrat yang merupakan jelmaan tali pusat Batari Uma, istri Bathara 
Guru-Petruk merupakan bagian dari gambaran leluhur Jawa Kedua, bentuk fisik Petruk dan atribut yang dikenakannya menyiratkan bahwa esensinya adalah sifat brahmana, sehingga tidak mengherankan Petruklah yang memangku Abimanyu menduduki tahta Hastina warisan Palasara (lakon Petruk Dadi Ratu) dan membakar jasad Abimanyu yang gugur di medan Kurusetra (lakon Ranjapan).

Sebagai brahmana yang mampu menyesuaikan diri, tidak mengherankan jika Petruk dapat bertransformasi ke wujud lain untuk menjawab perkembangan jaman, seperti dalam lakon Petruk Dadi Ratu bergelar Welgeduwelbeh (gambar 2), lakon PetrukDukun (gambar 3), menjadi kompeni (gambar 4), dan menjadi bagian dari wayang kontemporer (wayang hip-hop, gambar 5).

Hal yang menarik dari transformasi Petruk ke "Petruk" di atas adalah ciri khas dari wujud asli Petruk tidak berubah. Pada wayang klasik (Petruk Dukun dan Petruk Dadi Ratu), raut muka, tangan, kaki, dan senjatanya (pethel) tidak berubah. Perubahan terjadi pada atribut utama yang dikenakan, yakni atribut raja dan pendeta. Pada wayang Petruk Kompeni, yang berubah selain busana juga senjatanya (diganti pedang). Adapun pada wayang hip-hop perubahan wujud dan atributnya secara total terjadi. Petruk digambarkan sebagai penyanyi hip-hop lengkap dengan atributnya, namun ciri khas garis-garis wajah Petruk tidak berubah.

Wayang hip-hop adalah pertunjukan wayang kontemporer berbasis tradisi Wayang Kulit Purwa yang dikemas dengan balutan musik hip-hop. Estetika pertunjukannya bergaya jenaka menggunakan bahasa campuran Jawa dan Indonesia sehingga dapat dinikmati semua kalangan tanpa kehilangan unsur tradisinya. Wayang ini dicipta oleh Catur "Benyek" Kuncoro tahun 2010, sebagai resposns kreatif

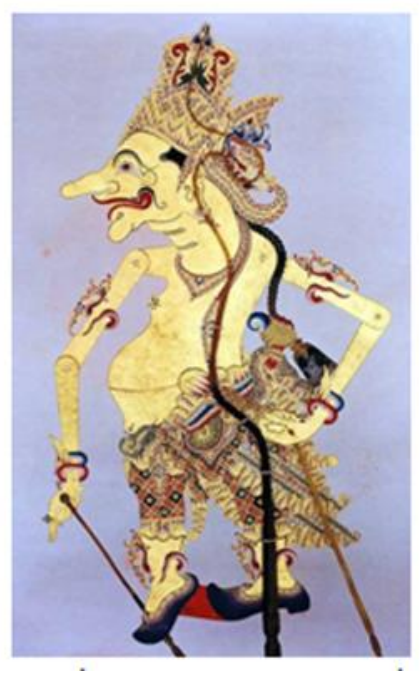

Gambar 2:

Wayang Petruk menjadi raja http://pitoyo.com/dunia wayang/galery/search. php?searchkey words= petruk\&sessionid $=8 \mathrm{~d} 123$ 03d637454487a97719d18a7 e5eds. Diunduh 5 Juli 2012

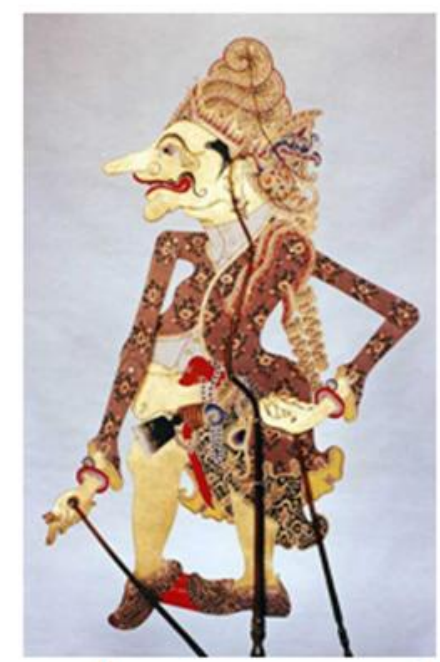

Gambar 3:

Wayang Petruk menjadi pendeta/dukun http://pitoyo.com/duniawayang/ galery/search.php?search keywords = petruk \&session id=8d12. Diunduh 5 Juli 2012

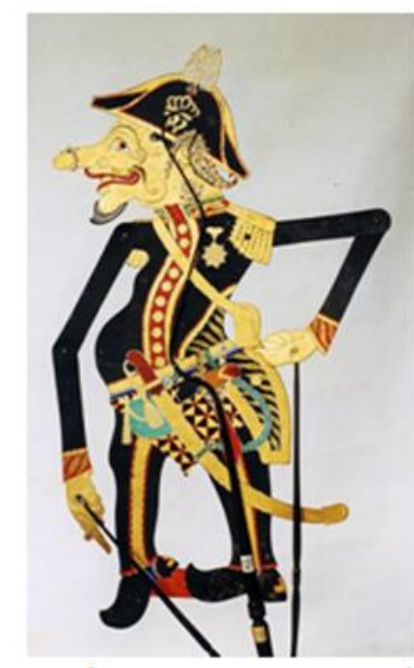

Gambar 4:

Wayang Petruk menjadi kompeni

http://javaneseart-culture. blog spot.com/2014/06/jenispetruk-menurut-asaldaerahnya.html. Diunduh 5 Juli 2012 


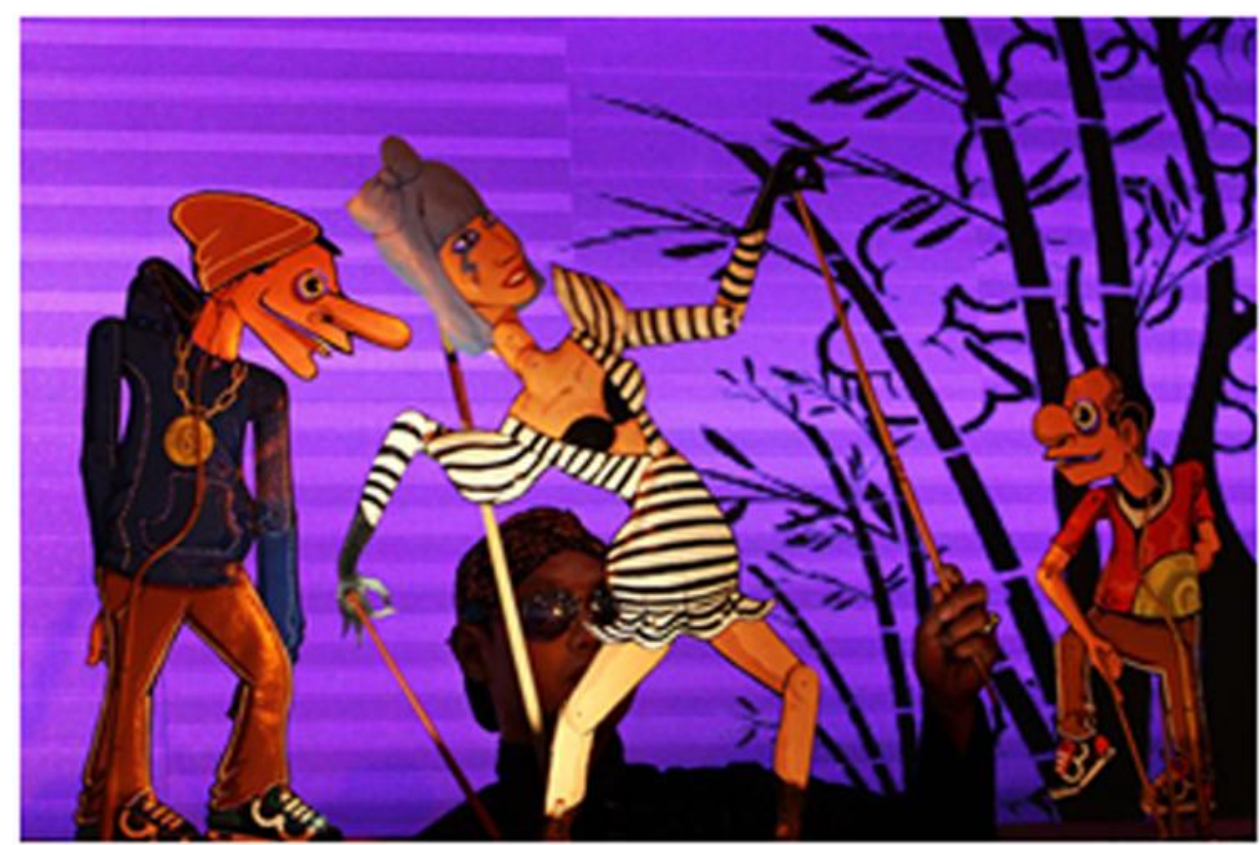

Gambar 5: Wayang Hip-hop, Patruk dan Gareng ketemu Lady Gaga Sumber: B. Kunto, Ed., "Mendekatkan Wayang pada Kaum Sosialita" dalam http://www.antaranews.com/berita/323857/mendekatkan-wayang-pada-kaumsosialita. Diunduh 27 Juli 2012

terhadap maraknya musik hip-hop di Yogyakarta, serta sebagai media pengenalan kembali seni pewayangan kepada generasi masa kini. Oleh sebab itu, pilihan panakawan termasuk Petruk sebagai tokoh yang divisualkan sesuai konteks kekinian cukup tepat, karena panakawan adalah ikon alam pikiran Jawa yang hidup sepanjang sejarah, dari jaman purba hingga Jawa modern. Panakawan ada dalam epik, mitos, ritual, hingga kehidupan nyata, sehingga tidak mengherankan jika dalam konteks seni pertunjukan mereka leluasa bertutur dengan bahasa Jawa, Indonesia, dan bahasa manca yang pernah menyinggahi Jawa.

\section{Sebuah Teori}

Teori pada dasarnya adalah suatu pernyataan dari hasil interpretasi terhadap fakta tertentu. Pernyataan tersebut dirumuskan dengan menghubungkan dua variabel yang berkausalitas universal, yang dalam tulisan ini adalah perbedaan pro- duksi estetik budaya mitis dan ontologis. Berpijak dari pengertian ini dan analisa terhadap transformasi Petruk ke "Petruk" di atas, dapat dirumuskan sebuah teori, bahwa transformasi nilai life force dari seni dalam budaya mitis ke budaya ontologis dapat berhasil hanya jika kreator secara komprehensif mampu: (1) menggali dan menginterpretasi substansi, esensi, dan nilai life force objek seni dalam bingkai budaya mitis yang akan ditransformasikan sesuai konteks penciptaannya; (2) mengonstruksi hasil point pertama ke dalam bentuk seni kekinian dengan menempatkan "ruh" nilai life force seni budaya mitis tersebut sebagai esensi (isi) karya; dan (3) menyajikan karya seni kekinian tersebut sesuai konteks penciptaannya. Teori ini setidaknya telah mendasari model konstruksi seni modern berbasis budaya lokal (Suharno, 2014: 328-336), dan model penciptaan karya seni berbasis kearifan lokal untuk anak usia dini (Suharno dan Rosarina Giyartini, 2013: 443-448). 


\section{SIMPULAN}

Tranformasi nilai-nilai life forse dalam seni dari budaya mistis ke ontologis setidaknya harus memperhatikan tiga hal yang saling berkait satu sama lain, yakni isi, bentuk, dan penyajian, baik dari sisi seni yang akan ditransformasikan (seni dalam bingkai budaya mitis), maupun hasil transformasinya (seni dalam bingkai budaya ontologis). Isi adalah nilai-nilai tertentu yang memiliki nilai life force. Wujud adalah benda seninya yang mewadahi isi. Penyajian adalah konteks penyajian karya, yakni dimana karya disajikan sesuai konteks penciptaan karya (untuk siapa dan untuk apa karya tersebut dibuat). Penyajian menjadi penting karena setiap ruang pameran memiliki konteksnya sendiri.

\section{Daftar Pustaka}

Agus Aris Munandar

2009 "Panakawan Konsep dan Perannya dalam Masyarakat Jawa Kuno: Kajian Arsitektur dan Sastera". Buku Elektronik Prosiding Seminar Internasional Naskah Nusantara Sabdopalon Nayagenggong dari Masa ke Masa. Jakarta, Perustakaan Nasional Republik Indonesia 6-7 Oktober 2009. Tersedia di http:// www.pnri.go.id/Attachment/Buku Elektronik/Nayagenggong/ 2009_11_17_12_26_39/document. pdf. Diunduh 12 Oktober 2014

Alfiana Wahyu Nur

2013 "Perubahan Budaya dalam Tradisi Nyadran di Kelurahan Ngantru Kecamatan Treanggalek Kabupaten Trenggalek Jawa Timur" dalam Jurnal Program Studi Pendidikan Bahasa dan Sastra Jawa Universitas Muhammadiyah Purworejo, Vol /0 2 / No. 01 / Mei 2013, hal. 104-116

Anung Tedjowirawan

2009 "Mitos Sekitar Penciptaan Teks Ramalan Jayabaya: Sabdo palon Naya Genggong". Buku Elektronik Internasional Naskah Nusantara Sabdopalon Nayagenggong dari Masa ke Masa. Jakarta, Perustakaan
Nasional Republik Indonesia 6-7 Oktober 2009. Tersedia di http:// www.pnri.go.id/Attachment/ BukuElektronik/Nayagenggong/ 2009_11_17_12_20_54/document. pdf. Diundūh $1 \overline{2}$ Oktober 2014

B. Kunto, Wibisono, ed. "Mendekatkan Wayang pada Kaum Sosialita". Tersedia di http://www.antaranews. com/berita/323857/mendekatkanwayang-pada-kaum-sosialita. Diunduh 27 Juli 2012

Bambang Riyanto Wiwoho

2001 “Wanda Panakawan Semar. Gareng, Petruk dan Bagong Gaya Kraton Yogyakarta". Skripsi Jurusan Pedalangan Fakultas Seni Pertunjukan ISI Yogyakarta

Bambang Sugiharto

2008 "Gelagat Post-Estetik dalam Seni Kontemporer". Tersedia di http:// bambarto.blogspot.com/2008/06/ gelagat-post-estetik-dalamseni.html. Diunduh 2 Januari 2012.

Budya Pradipta

2009 "Sabdapalon antara Kenyataan dan Mitos". Buku Elektronik Prosiding Seminar Internasional Naskah Nusantara Sabdopalon Nayagenggong dari Masa ke Masa. Jakarta, Perustakaan Nasional Republik Indonesia 6-7 Oktober 2009. Tersedia di http://www.pnri.go.id/Attach ment/Buku Elektronik/Nayagen ggong/2009_ 11_17_10 56_33/ document.pdf. Diunduh 12 Oktober 2014

Dalang Gampang

1956 "Bab Wandaning Wayang Panaka wan", dalam Madjalah Padalangan Panjangmas, Tahun IV, No. 3, 10 April 1956. Yogyakarta: Paguyuban Anggarakasih . Hal. 15-16.

Dipokusumo

2009 "Sabdapalon Nayagenggong Nagih Janji: Makna dan pemahaman dari masa ke masa". Buku Elektronik Prosiding Seminar Internasional Naskah Nusantara Sabdopalon Nayagenggong dari Masa ke Masa. Jakarta, Perustakaan Nasional Republik Indonesia 6-7 Oktober 2009. Tersedia di http://www. pnri. 
go.id/Attachment/BukuElektronik/ Nayagenggong/2009_11_17_10 52_20/ document. pdf. Diunduh $1 \overline{2}$ Oktober 2014

Dwi Marianto

2010 "Relasi Bolak-balik Antara Seni dan Daya Hidup" dalam Panggung, Jurnal Ilmiah Seni dan Budaya STSI Bandung vol. 20 No. 2 April-Juni 2010: 143-158

Earl Drake

2012 Gayatri Rajapatni: Perempuan di Balik Kejayaan Majapahit. Yogyakarta: Ombak.

Edi Sedyawati

2009 "Panakawan di Masa Majapahit". Buku Elektronik Prosiding Seminar Internasional Naskah Nusantara Sabdopalon Nayagenggong dari Masa ke Masa. Jakarta, Perustakaan Nasional Republik Indonesia 6-7 Oktober 2009. Tersedia di http:// www.pnri.go.id/Attachment/Buku Elektronik/Nayagenggong/ 2009_11_17_10_48_46/document.p df. Diunduh 12 Oktober 2014

Heddy Shri Ahimsa Putra

2001 Strukturalisme Levi-Strauss : Mitos dan Karya Sastra. Yogyakarta: Galang Press.

Hendrawan Riyanto

2002 "Form Follows Myth: Interpretasi Mitos Kosmogoni dan Mitos Asal-usul dalam Seni Rupa Ritus Kini". Tesis Program Magister Program Pascasarjana Institut Teknologi Bandung

I Kuntara Wiryamartana

2009 "Obrolan Ki Petruk". Buku Elektronik Internasional Naskah Nusantara Sabdopalon Nayagenggong dari Masa ke Masa. Jakarta, Perustakaan Nasional Republik Indonesia 6-7 Oktober 2009. Tersedia di http://www.pnri.go.id/ Attachment/BukuElektronik/ Nayagenggong/ 2009_11_17_10 39_32/document.pdf. Diunduh 12 Oktober 2014

Jakob Sumardjo

2006 Estetika Paradoks. Cetakan Pertama. Bandung: Sunan Ambu Press
Junus Satrio, Atmodji

2009 "Dwarapala yang Santun dari Muarajambi". Buku Elektronik Prosiding Seminar Internasional Naskah Nusantara Sabdopalon Nayagenggong dari Masa ke Masa. Jakarta, Auditorium Perustakaan Nasional Republik Indonesia 6-7 Oktober 2009. Tersedia di http://www.pnri.go.id/Attachment/BukuElektronik/Nayagenggong/2009_11_17_10 43 52/document. pdf. Diunduh 12 Oktober 2014

Karkono Kamajaya Partokusumo

1995 Kebudayaan Jawa Perpaduannya dengan Islam. Yogyakarta: Ikatan Penerbit Indonesia Cabang Yogyakarta

Ki Musa Al Machfoeld

1976 Priyagung, Dar-Us-Salam Almarhum Drs Sosrokatono Di Jln. Pangkur No 7 Bandungg: Langkah-Laku, Tata-Hidup, Kehidupan dan Kepribadiannya Ditinjau dari Segi Ke-Islaman (Yogyakarta: Yayasan Sosrokartanan.

Lombard, Dennys

1996 Nusa Jawa: Silang Budaya, Warisan Kerajaan-kerajaan Konsentris 3. Jakarta: Gramedia Pustaka Utama

Manu J. Widyaseputra

2012 "Mahîrakaca; Kaca sebagai Udyana menurut Lampahan Tumurunipun Taman Maerakaca dalam Tradisi Wayang Yogyakarta", dalam Jumantara Vol. 3 No. 2/2012, 13 - 54

Poerbatjaraka

1957 Kepustakan Djawi. Jakarta: Penerbit Djambatan

Poerwadarminta

1939 Baoesastra Djawa. Batavia: J.B. Wolters' Uitgevers Maatschappij.

Sapardi Djoko Damono

2009 "Mengapa Satria Perlu Panakawan?". Buku Elektronik Prosiding Seminar Internasional Naskah Nusantara Sabdopalon Nayagenggong dari Masa ke Masa. Jakarta, Perustakaan Nasional Republik Indonesia 6-7 Oktober 2009. Tersedia di http://www.pnri.go.id/Attachment/BukuElektronik/Nayagenggong/20091117 1031 24/ document. pdf. Diunduh 12 Oktober 2014. 
Soelarto

1993 Garebeg di Kasultanan Yogyakarta. Yogyakarta: Kanisius

Soenarto Timoer

1988 Serat Wewaton Pedhalangan Jawi Wetanan, Jilid I. Jakarta: Balai Pustaka.

Soerjono Soekamto

1985 Kamus Sosiologi. Jakarta: Rajawali

Stange, Paul

1998 Politik Perhatian: Rasa dalam Kebudayaan Jawa. Yogyakarta: LKiS

Suharno

2014 "The Esthetic Transformation of Mysthical to Ontological Culture: The Model of Local Culture-Based Modern Art Construction", dalam Kasiyan, dkk., ed. Proceeding The 1\# International Conference for Arts and Arts Educations on Indonesia (ICAAE) "Rethingking the Human Dignity and Nation Identity: A Review Perspective of Arts an Arts Education". Yogyakarta: UNY Press

2009 "Potret Perempuan Jawa dalam Prombon dan Limbukan", dalam Endang Caturwati, ed., Pesona Perempuan dalam Sastra dan Seni Pertunjukan. Bandung: Sunan Ambu Press

Suharno dan Rosarina Giyartini

2013 "Model Penciptaan Karya Seni Berbasis Kearifan Lokal untuk Anak Usia Dini", dalam Tatat Hartati, Mubiar Agustin, dan Mubarok Sumantri, ed., Prosiding Konferensi Nasional Anak Usia Dini dan Pendidikan Dasar SPS UPI Menyongsong Generasi Emas 2045. Bandung: Prodi Pendidikan Dasar SPS UPI Bandung

2000 Filsafat Seni. Bandung: ITB

Toeti Heraty Noerhadi

1984 Aku dalam Budaya: Suatu Telaah Filsafat Mengenai Hubungan SubyekObyek. Cetakan pertama. Jakarta: Pustaka Jaya
2009 “Sûrya dalam Pratiophâ dan Rasavyañjaka: Hermeneutik Bhîma dalam Kakavin Ambœraya Menurut Teori Dhvani Ãnandvardhana", dalam Humaniora, Jurnal Budaya, Sastra dan Bahasa Fakultas Ilmu Budaya, UGM. Volume 21 No 1 Februari 2009, 1-16

2007 “Bantal Tilu Jamparing di Kuruetra: Bisma Gugur Menurut Tradisi Mãhãbharata", dalam Humaniora, Jurnal Budaya, Sastra dan Bahasa Fakultas ilmu Budaya, UGM. Volume 19 No 2 Juni 2007, 119-134

2001 "Relevansi Analisis Tekstual dan Kontekstual untuk Memahami Pentas Wayang Kulit dalam Masyarakat Jawa Masa Kini: Studi Kasus tentang Lakon Pandu Swarga" dalam Humaniora, Jurnal Budaya, Sastra dan Bahasa Fakultas ilmu Budaya, UGM. Volume XIII, No. 2/2001, 194-203

Trias Yusuf

2009 "Panakawan dalam Tradisi Kesenian Pesisir Jawa". Makalah Seminar Internasional Naskah Nusantara Sabdopalon Nayagenggong dari Masa ke Masa. Jakarta, Perustakaan Nasional Republik Indonesia 6-7 Oktober 2009. Tersedia di http:// www.pnri.go.id/Attachment/Buku Elektronik/Nayagenggong/ 2009_11_17_10_26_35/document. pdf. Diunduh $1 \overline{2}$ Oktober 2014

Zoetmulder

1983 Kalangwan Sastra Jawa Kuno Selayang Pandang. Jakarta: Jambatan.

\section{Sumber Lain}

Kaset Wayang Kulit Purwa lakon Semar Bangun Kayangan dalang Ki Hadi Sugito. Semarang: Pusaka Record, 2004

Kaset Wayang Kulit Purwa lakon Semar Gugat dalang Ki Hadi Sugito. Sema-rang: Dahlia Record , 2002 
http://pitoyo.com/duniawayang/galery/ search.php? searchkeywords=petruk\& sessionid=8d12 303d637454487a97719 d18a7e5eds. Diunduh 5 Juli 2012

http://pitoyo.com/duniawayang/galery/ search.php? search keywords=petruk\& sessionid=8d12. Diunduh 5 Juli 2012 http://javaneseart-culture.blogspot.com/ 2014/06/jenis-petruk-menurut-asaldaerahnya.html. Diunduh 5 Juli 2012 